\title{
DE BESLOTEN NAAMLOZE VENNOOTSCHAPPEN IN DE NIEUWE BELASTINGONTWERPEN
}

\author{
door J. Kooiman
}

\section{INLEIDING}

Bij het merendeel van de besloten N.V.-en zijn leiding en eigendom niet of in beperkte mate gescheiden. De aandeelhouders - niet zelden familie-leden - zijn tevens oprichters en directeuren. Sommige dezer N.V.-en worden na het overlijden van de oprichters geliquideerd, andere groeien uit tot open N.V.-en, terwijl een aantal als besloten N.V. blijft voortbestaan onder leiding van directeuren die veelal slechts een relatief klein aantal aandelen bezitten. In de navolgende beschouwingen wordt in het bijzonder gedacht aan die categorie van besloten N.V.en, waarbij leiding en eigendom nog grotendeels in dezelfde handen zijn. Dikwijls zijn het groei-familie vennootschappen.

In zeer vele gevallen bezitten de aandeelhouders-directeuren naast hun aan de N.V. gebonden vermogen weinig of geen privé-vermogen. Dit geldt niet alleen voor kleine doch ook voor middelgrote en soms zelfs voor grote N.V.-en. Na betaling van I.B. (en V.B. over de de waarde der aandelen) zal de besparing uit het van de N.V. verkregen arbeidsinkomen - salaris en tantième - doorgaans niet hoog zijn. De winst van de N.V. vloeit voor bijna de helft in de vorm van Vpb. naar de fiscus. Voor zover het overblijvende deel door de N.V. kan worden gemist, zou het als dividend kunnen worden uitgekeerd. Dit zou evenwel bij de aandeelhouders heffing van I.B. betekenen naar een hoog tarief - progressie aan de top van het inkomen - waardoor van de oorspronkelijke winst van de N.V. in vele gevallen circa $80-85 \%$ aan de fiscus ten goede zou zijn gekomen en slechts 15-20\% aan de aandeelhouders. Mede door deze fiscale gevolgen blijft dividenduitkering of geheel achterwege of is zij van bescheiden omvang. De fiscus moet voorlopig genoegen nemen met de - lang niet geringe - betaling van $\mathrm{Vpb}$. De claim I.B. op het meerdere bevriest. Het aantal graden onder nul hangt nauw samen met de hoogte van de I.B.-tarieven en is ten onzent daarom aanzienlijk.

De hier geschetste situatie leidt dikwijls tot moeilijkheden van tweeërlei aard, t.w.:

a. De N.V. raakt onder-gekapitaliseerd en wordt daardoor in haar groei belemmerd. Zouden de door de N.V. ingehouden winsten worden aangewend tot herkapitalisatie, dan is ook volgens het nieuwe wetsontwerp I.B. in principe de nominale grootte der herkapitalisatie onderworpen aan I.B. naar het progressieve tarief.

b. Het ontbreken van een privé-vermogen van enige betekenis naast het aan de N.V. gebonden vermogen geeft bij overlijden schier onoplosbare puzzels ten aanzien van boedelscheiding en betaling van successierecht.

In het licht van het bovenstaande wordt hieronder een korte beschouwing gewijd aan de volgende onderwerpen uit de nieuwe wetsvoorstellen:

- de tariefsreductie Vennootschapsbelasting over uitgedeelde winsten;

- de continue herkapitalisatie-regeling;

- het aanmerkelijk belang en de inkoop van eigen aandelen door de N.V. 
Volgens artikel 21 van het wetsontwerp $\mathrm{Vpb}$. wordt de $\mathrm{Vpb}$. verminderd met $15 \%$ van de over het jaar gedane uitdelingen van winst, doch maximaal over twee derden van het belastbare bedrag.

Door het onevenredig hoge tarief I.B. daalt echter de totale belastingheffing van uitgedeelde winsten - dus Vpb. en I.B. tezamen - in vele gevallen slechts met circa $5 \%$ en wordt dus ,gereduceerd" van $80-85 \%$ tot $75-80 \%$. Bovendien geldt de tariefsreductie - door de maximering tot $2 / 3$ van het jaarlijkse belastbare bedrag - niet wanneer winsten eerst in de N.V. worden opgepot en later, b.v. om successierechten te kunnen betalen, in één keer worden uitgedeeld.

Het staat daarom te vrezen dat de tariefsreductie $\mathrm{Vpb}$. voor de besloten N.V.-en en haar aandeelhouders weinig betekenis zal hebben.

Ik moge nog wijzen op de Duitse regeling, volgens welke het tariefsverschil Körperschaftssteuer voor uitgedeelde en niet-uitgedeelde winsten $36 \%$ is en op de nog verdergaande Engelse regeling, volgens welke de door de N.V. betaalde ,,income tax" als een voorheffing wordt behandeld, ongeacht wanneer de winstuitdeling plaats vindt.

\section{DE CONTINUE HERKAPITALISATIE-REGELING}

Zoals in paragraaf 1 reeds vermeld, wordt in het nieuwe wetsontwerp I.B. de voor uitreiking van bonusaandelen bestaande regeling - heffing van I.B. naar progressief tarief over de nominale waarde - gehandhaafd. Deze regeling is practisch prohibitief, waardoor een aanpassing van het aandelenkapitaal aan de groei van het bedrijf wordt belemmerd. In het verleden heeft men daarom tot driemaal toe $(1942,1951$ en 1957) de mogelijkheid tot herkapitalisatie opengesteld, waarbij de I.B.-heffing wel plaats vond, doch naar een matig tarief.

De continue herkapitalisatie-regeling in artikel 49 van het wetsontwerp I.B. verleent grotendeels dezelfde faciliteiten als de wet op de Herkapitalisatie 1957. Het speciale tarief is weer $20 \%$. De N.V. kan ook de belasting weer voor haar rekening nemen door een aanvullend dividend in contanten uit te keren van maximaal $25 \%$ van de nominale kapitaalsvergroting, op welk dividend eveneens het tarief van $20 \%$ van toepassing is. Voorts moet de bonus weer minstens $25 \%$ van het gestort kapitaal vóór de herkapitalisatie uitmaken. Tenslotte is ook de sanctie bij terugbetaling van aandelenkapitaal nà herkapitalisatie gehandhaafd: Volgens artikel 22 van het wetsontwerp Vpb. moet in dat geval $25 \% \mathrm{Vpb}$. worden voldaan over het nominale bedrag van de kapitaalsteruggave. De termijn is nu gesteld op 10 jaar, bij de vorige regeling was dit 5 jaar.

Aan bovenstaande uit vroegere regelingen reeds bekende voorwaarden zijn thans een aantal beperkende bepalingen toegevoegd. Vereist is n.l. dat in de voorafgaande 10 jaren:

a. dividenden zijn uitgekeerd tot tenminste een bedrag gelijk aan het dubbele van de kapitaalsvergroting;

b. geen inkoop van aandelen of terugbetaling van kapitaal heeft plaats gehad;

c. niet reeds een herkapitalisatie met toepassing van het tarief I.B. van $20 \%$ werd doorgevoerd. 
Van de onder b. genoemde voorwaarden kan de Minister afwijking toestaan, van de onder a. en $c$. genoemde voorwaarden niet.

Een aantal besloten N.V.-en, n.l. die waarbij leiding en eigendom grotendeels in verschillende handen zijn en die veelal niet meer in het groei-stadium verkeren, plegen - evenals de open N.V.-en - regelmatig dividend uit te keren. Voor deze N.V.-en wordt de herkapitalisatie-regeling door de genoemde extra beperkingen weliswaar sterk aan banden gelegd, doch zij behoudt althans enige betekenis. Voor verreweg het grootste deel der familie-N.V.-en echter wordt de hele regeling door de nieuwe voorwaarden - met name door die onder a. genoemd - tot een dode letter. Indien een N.V. haar kapitaal met $100 \%$ wil vergroten tegen het gematigde tarief, moet zij in de voorafgaande 10 jaar gemiddeld minstens $20 \%$ dividend uitgekeerd hebben. Aan deze voorwaarde zal practisch geen enkele familie-N.V. voldoen.

Het uitgangspunt van de regeling is m.i. onjuist, waarover nader in paragraaf 5. Thans moge ik volstaan met op te merken dat, wanneer men het bedrijfsleven inderdaad uit de impasse ten aanzien van de onderkapitalisatie wil helpen, geen beperkingen moeten worden gemaakt die verder gaan dan nodig is ter bescherming van de redelijke belangen van de fiscus. De voorwaarden van de wet op de Herkapitalisatie 1957 zijn daartoe m.i. voldoende. $\mathrm{Bij}$ handhaving van de reeds vermelde bepaling van artikel 22 van het wetsontwerp $\mathrm{Vpb}$. is de verleiding om normale jaardividenden via herkapitalisatie op fiscaal goedkope wijze naar de aandeelhouders te laten gaan, niet groot meer. Om dit te bereiken moet men achtereenvolgens:

- herkapitaliseren à raison van $20 \%$ I.B. en $2 \frac{1}{2} \%$ registratierecht;

- 10 jaar wachten;

- het aandelenkapitaal weer terugbetalen.

Zou binnen de 10 jaar terugbetaling van kapitaal plaats vinden, dan loopt het fiscale offer op tot $331 / 3 \%$ I.B. (in de vorm van $50 \% \mathrm{Vpb}$.) plus $21 / 2 \%$ registratierecht.

De regeling met betrekking tot de inkoop van eigen aandelen wordt in paragraaf 4 hierna besproken.

De bepaling dat een gefacilieerde herkapitalisatie slechts eens in de 10 jaar mag plaats vinden, kan m.i. eveneens gevoegelijk worden gemist. Zou men een bepaling als deze niet willen schrappen, dan zou een termijn van 5 jaar stellig voldoende zijn. Het zou daarbij elegant zijn om de herkapitalisatie volgens de wet op de Herkapitalisatie 1957 niet te laten meetellen.

Een permanente herkapitalisatie-regeling is op zichzelf gewenst zo niet noodzakelijk. Toch zou voor de hier besproken categorie N.V.-en naar mijn gevoelen het ontbreken van een permanente regeling te verkiezen zijn boven een ongewijzigde aanvaarding van artikel 49 van het huidige wetsontwerp I.B. Een ontkrachte permanente regeling zal immers een belemmering zijn om af en toe wat stoom af te blazen - zoals dat in het verleden reeds enige malen is geschied - door het scheppen van een wèl effectieve tijdelijke regeling. Het is te hopen dat een eventuele amendering van het ontwerp-artikel 49 niet halfslachtig zal zijn. 
4. HET AANMERKELIJK BELANG EN DE INKOOP VAN EIGEN AANDELEN DOOR DE N.V.

De belastingheffing over winsten bij vervreemding van een aanmerkelijk belang (hierna af te korten als a.b.) is gehandhaafd. In ons belastingstelsel, dat geen vermogenswinstbelasting kent, past de a.b.-heffing niet. De invoering geschiedde door de Duitsers in 1941 zonder een eigenlijke motivering. Sindsdien heeft men de heffing verdedigd met de stelling dat de a.b.-houder pseudo-ondernemer is. De feitelijke regeling paste maar zeer ten dele op dit uitgangspunt.

In de M.v.T. op het gewijzigde wetsontwerp I.B. wordt deze stelling niet langer geponeerd, doch wordt de regeling uitsluitend aangediend als een middel om een lek in de belastingheffing te voorkomen. Door zijn machtspositie heeft de a.b.houder het in de hand - aldus wordt geargumenteerd - om geen of matige dividenden uit te keren, en daardoor de heffing van I.B. te voorkomen. Desniettemin kan hij door verkoop van zijn aandelen de in de N.V. verzamelde winst realiseren.

Geschiedt de verkoop aan een bedrijfsvermogen, dan kan m.i. redelijkerwijs geen bezwaar bestaan tegen heffing van I.B. over de vervreemdingswinst, aangezien de claim I.B. op de in de verkoopprijs tot uitdrukking gekomen vennootschapsreserves teloorgaat (hoewel herleving mogelijk is, nl. bij latere verkoop aan een particulier).

Is de koper een natuurlijke persoon, die niet bedrijfsmatig handelt, dan blijft de claim I.B. intact, zodat de heffing achterwege zou kunnen blijven. In verband met de veronderstelde bovenmatige reservering is voor een fiscale afrekening met de eerste houder ook in dit geval wel iets te zeggen, mits het terzake geheven bedrag op de later te heffen I.B. over door de N.V. te verrichten uitkeringen in mindering wordt gebracht.

Uitgaande van de nieuwe rechtsgrond wordt een aantal wijzigingen in het bestaande systeem voorgesteld, die het regime nogal verlichten, $t$.w.:

1. De heffing zal voortaan geschieden naar een vast tarief van $20 \%$.

2. De kostprijs van het a.b. wordt gesteld op tenminste $100 \%$, ook al is de werkelijke kostprijs lager.

3. Bij het belasten van liquidatie-uitkeringen van N.V.-en vindt een zekere verrekening plaats terzake van vroeger betaalde I.B. over winst uit a.b., doch alleen wanneer de aandelen gedurende tenminste 10 jaren onafgebroken tot een a.b. hebben behoord (artikel 49a van het wetsontwerp I.B.). Deze verrekening is vrij ruw. De regeling kan er toe leiden dat tòch over bepaalde delen van de vennootschapswinst tweemaal I.B. wordt betaald en omgekeerd dat vermindering van I.B. over liquidatie-uitkeringen wordt verleend zonder dat vroeger reeds I.B. is geheven. Bovendien blijft de verrekening beperkt tot liquidatie-uitkeringen, terwijl zij in principe zou moeten worden uitgebreid tot gewone dividenden, bonusaandelen, inkoop van eigen aandelen etc. Al deze oneffenheden zijn aanvaard omdat de regeling anders al te gecompliceerd zou worden.

4. Het eigen bezit dat niet uitgaat boven de $5 \%$, is voortaan vrijgesteld. Het telt echter wèl mee bij verwanten die meer dan $5 \%$ bezitten. De grens is overigens $25 \%$ gebleven. Het stellen van een procentuele grens 
- wèlk percentage men ook kiest - is in het kader van de nieuwe ratio altijd willekeurig.

5. De bestaande „fusie-regeling” van artikel 21a van het huidige Besluit I.B. is in artikel $34 \mathrm{a}$ van het wetsontwerp vrijwel zonder wijzigingen overgenomen.

6. Voortaan wordt ook rekening gehouden met verliezen uit a.b. Daar het heffingspercentage over a.b.-winsten $20 \%$ is, worden ook de aan te rekenen verliezen tegen dit tarief in mindering gebracht krachtens een speciale in artikel $49 \mathrm{~b}$ van het wetsontwerp I.B. geregelde procedure.

Naast deze verlichtingen worden ook enkele maatregelen voorgesteld, die het bestaande regime verzwaren, t.w.:

7. Voortaan vindt de heffing ook plaats bij schenking of verkoop tegen te lage prijs. In de plaats van de overdrachtsprijs treedt dan de ,waarde in het economische verkeer". Deze regeling betekent dat waardering van pakketten incourante aandelen voor I.B.-doeleinden van belang wordt. Dit zal vermoedelijk - gezien de doorgaans grotere fiscale belangen dan bij waardering voor V.B., schenkings- of successierecht - tot vele waarderingsgeschillen aanleiding geven.

8. Bij overlijden van de a.b.-houder blijft de claim I.B. op de tot de sterfdatum opgetreden waardevermeerdering voortaan voor de fiscus behouden. Voor de erfgenamen is de kostprijs bij latere vervreemding niet langer de successiekoers, doch de kostprijs van de erflater. Niet duidelijk is hoe deze moet worden bepaald, indien de erflater de aandelen zèlf ook heeft geërfd. Moet in dat geval naar de kostprijs van de vroegere erflater worden teruggegaan? Als dat de bedoeling is, zullen uitgebreide speurtochten in vergeelde documenten tot de fiscale practijk gaan behoren. Op grond van de tekst van artikel 34 lid 8 van het wetsontwerp I.B. meen ik dat slechts moet worden teruggegaan tot de erflater van de vervreemder, m.a.w. dat de belasting op de waardestijging van a.b.-en wordt belast tot in de tweede generatie. Logisch is deze scheidingslijn niet.

Vermeld zij nog dat de erfgenamen desgewenst ook met de fiscus kunnen afrekenen tegen het tarief van $20 \%$. Dit zal waarschijnlijk weinig gebeuren. De afrekening met de fiscus behoeft bij toekomstige vervreemding immers nooit tegen een hoger tarief dan $20 \%$ te geschieden.

Ervan uitgaande dat het wenselijk is om de heffing over winsten uit a.b. te continueren (waarover straks nader), kunnen de maatregelen sub 7 en 8 als technische verbeteringen worden gezien. Een tweetal amendementen zijn echter aanbevelenswaardig:

\section{op sub 7 hiervoor:}

Daar schenking van aandelenpakketten vrijwel steeds geschiedt aan toekomstige erfgenamen zou naast dadelijke afrekening met de fiscus de mogelijkheid tot doorschuiving van de fiscale kostprijs van de schenker moeten worden gegeven. De zo verwante figuren van schenking en overgang bij overlijden zouden dan op analoge wijze zijn geregeld. Tevens zouden lastige waarderingsgeschillen worden vermeden. 


\section{op sub 8 hiervoor:}

Een overgangsregeling zou moeten voorkomen, dat bij de huidige bezitters waardestijgingen van vroegere bezitters worden belast, daar eerstgenoemde bezitters reeds jarenlang in de overtuiging hebben geleefd dat hun kostprijs gelijk is aan de successiekoers van hun erflater. Uit een oogpunt van billijkheid lijkt dit gewenst. Bovendien ondervangt het (voorlopig) de bovenvermelde moeilijk oplosbare vraag hoever in het verleden moet worden teruggegaan.

Alle wijzigingen overziende, mag wel worden gesproken van een belangrijke verlichting van het regime, vooral door de invoering van het vaste tarief van $20 \%$. Dit - gematigd - optimisme over de nieuwe regeling wordt echter verstoord door nòg een wijziging die in artikel 34 lid 1 van het wetsontwerp I.B. is verscholen. Krachtens deze bepaling geldt de a.b.-regeling niet, indien de winst bij verkoop van de aandelen tevens als (o.a.) inkomen uit vermogen is aan te merken. Zulks is volgens de Hoge Raad het geval bij inkoop van eigen aandelen door de N.V. Zie arrest d.d. 14 november 1956, BNB 1957/20, waarbij werd beslist dat al hetgeen bij zulk een inkoop boven pari wordt betaald als opbrengst van de aandelen moet worden beschouwd. Op deze opbrengst is het progressieve tarief I.B. van toepassing. Daar echter bij de huidige regeling deze opbrengst tevens winst uit a.b. is, is in vele gevallen van inkoop door de N.V. tòch het gematigde tarief van toepassing.

Bij familie-N.V.-en past verkoop van de aandelen aan derden, ook wanneer contanten nodig zijn voor boedelscheiding of betaling van successierechten, dikwijls geheel niet in de verhoudingen. Inkoop van eigen aandelen door de N.V. nog tijdens het leven van de oprichter der N.V., die gewoonlijk nog een lage kostprijs a.b. heeft, is dan niet zelden de aangewezen weg. De I.B.-heffing geschiedt dan naar het gematigde tarief. De hantering van het progressieve tarief I.B. bij inkoop van eigen aandelen in het nieuwe wetsontwerp I.B. betekent, dat deze mogelijkheid wordt afgesneden.

Evenals bij herkapitalisatie zou het m.i. voldoende zijn, wanneer er tegen gewaakt wordt, dat normale jaardividenden via inkoop van eigen aandelen op fiscaal goedkope wijze naar de aandeelhouders gaan. Zou de inkoop vrij van I.B. kunnen geschieden, dan zou nà de inkoop opnieuw kapitaal kunnen worden uitgegeven om vervolgens de inkoop te kunnen herhalen. Om dit te voorkomen, is een regeling nodig.

Bij zulk een regeling moet worden bedacht, dat het opbrengst-gedeelte van de koopsom normaliter een winst voorstelt, die gedurende een reeks van jaren is behaald, m.a.w. de ,uitkering" bij inkoop van eigen aandelen vertoont veel overeenkomst met een liquidatie-uitkering. Toepassing van het tarief artikel 48 (20-40\%) ligt daarom voor de hand. Dit lijkt bovendien redelijk in het gehele kader van de belastingheffing van besloten N.V.-en, waarover nader in paragraaf 5.

Indien men elke weg afsnijdt om op fiscaal gunstige condities middelen aan de N.V. te onttrekken - b.v. ter betaling van hoge bedragen wegens successierechten zullen de aandeelhouders van de onderhavige categorie van N.V.-en dikwijls in een impasse geraken.

Uit het bovenstaande moge blijken dat een heffing over vervreemdingswinsten 
a.b. als middel om een lek in de heffing te voorkomen, mij op zichzelf wel aanvaardbaar voorkomt. Dit neemt niet weg, dat tegen de regeling een aantal practische bezwaren kunnen worden aangevoerd.

a. De heffing van deze belasting belemmert dikwijls transacties die niet alleen voor de betrokken partijen, doch ook uit een algemeen economisch oogpunt zeer gewenst zijn. De practijk dwingt daarom in vele gevallen naar het zoeken - gewoonlijk in overleg met de fiscus - van een fiscaal goedkope oplossing. De noodzaak daartoe is zó evident, dat als uitlaatklep de ingewikkelde z.g. „fusie-regeling” is geschapen, die in artikel 34 a van het wetsontwerp I.B. is overgenomen en dus nu als permanent is bedoeld. De strekking van deze regeling is om de fiscale claim uit hoofde van het a.b. - welke claim toch al zo sterk in de ijskast zit - ingeval van fusie nog verder te bevriezen. Zou een claim op lange termijn, die bij „dreigende" realisatie opnieuw met kunst- en vliegwerk moet worden verschoven, veel waarde hebben voor de fiscus? In de gevallen waarin de fusie-regeling niet van toepassing is, gaat een op zichzelf zeer nuttige transactie dikwijls vanwege de dreigende a.b.-heffing niet door.

De vraag mag daarom worden gesteld of de zuiver fiscale en de algemeen economische belangen bij de beslissing tot handhaving van de a.b.-heffing wel juist tegen elkaar zijn afgewogen.

b. Gezien de nieuwe ratio van het a.b. - een compensatie voor het bovenmatig reserveren - moet het criterium voor het a.b. eigenlijk niet langer zijn het bezit van een bepaald percentage van het totale aandelenkapitaal, doch het al of niet bovenmatig reserveren. Naar dit criterium zouden talloze aandelenpakketten van meer dan $25 \%$ in besloten N.V.-en niet langer een a.b. vormen. Met name wanneer zich in de tweede of derde generatie een belangrijke scheiding tussen leiding en eigendom voltrekt, komt ook de besloten N.V. veelal tot een normale dividenduitkering.

Anderzijds zijn er aandelen in open N.V.-en, waarvan het dividend geen weerspiegeling is van de gemaakte winsten, met name de groeifondsen.

Het lijkt mij evenwel niet doenlijk het criterium „bovenmatig reserveren” op bevredigende wijze te formuleren en te hanteren.

c. Bij verkoop aan een andere natuurlijke persoon is aan een a.b.-heffing als middel tegen een lek geen behoefte, omdat geen lek ontstaat. Zoals in de aanhef van deze paragraaf reeds vermeld, is desondanks een fiscale afrekening met de verkoper van het a.b.-pakket ook in dit geval wel verdedigbaar, mits deze heffing als "voorheffing” op latere uitdelingen door de N.V. fungeert. In artikel $49 \mathrm{a}$ van het wetsontwerp I.B. is inderdaad een dergelijke regeling gemaakt (zie onder 3 hiervóór) die echter om al te grote complicaties te vermijden zóveel ruwheden vertoont, dat zij behoorlijk ,lekt”.

d. Hoewel de a.b.-regeling de fiscus waarschijnlijk relatief niet al te veel oplevert, wordt een zeer ingewikkelde regeling voorgesteld (in het nieuwe wetsontwerp I.B. belichaamd in de artikelen $34,34 a, 34 b, 49 a$ en $49 b$ ). Uit hetgeen onder b. en c. werd opgemerkt moge blijken, dat de regeling desondanks nog zeer gebrekkig is.

Het vorenstaande leidt gemakkelijk tot de conclusie dat men de a.b.-heffing, zij het niet op principiële dan toch op practische gronden, beter kan afschaffen. 
Toch moet vóórdat deze conclusie wordt getrokken, nog één vraag onder ogen worden gezien, nl. of de a.b.-heffing niet noodzakelijk is vanwege haar preventieve werking.

Het lijkt mij toe dat verkoop van a.b.-aandelenpakketten aan derden niet of slechts zelden zal plaats vinden alleen omdat dat eventueel fiscaal gunstig ligt. Er resteert dan nog de - reeds besproken - inkoop van eigen aandelen door de N.V. en de inbreng in een ,eigen" zaakvermogen, waarbij met name gedacht moet worden aan inbreng van een a.b.-pakket in een holding. Dit zou zonder a.b.-heffing inderdaad een eenvoudige methode zijn om de claim I.B. teniet te doen. Hiervoor ware een voorziening te treffen in analogie met die omtrent herkapitalisatie. Bij inbreng van een a.b.-pakket in een holding zou het verschil tussen de nominale grootte van het aandelenkapitaal van de oude en de nieuwe N.V. met $20 \%$ I.B. belast kunnen worden. Een gefacilieerd dividend in contanten van $25 \%$ zou hierbij eveneens passen. Dit zou door de „oude” N.V. betaald kunnen worden.

Een andere oplossing - eventueel ter keuze van belanghebbenden - zou zijn de fiscale claim bij inbreng in een holding niet af te rekenen, doch door te schuiven. Dit zou kunnen geschieden op overeenkomstige wijze als bij de huidige fusieregeling, zie artikel $34 \mathrm{a}$ lid 4 van het wetsontwerp I.B.

Onder het voorbehoud dat naast een regeling omtrent de inkoop van eigen aandelen een regeling terzake van de inbreng in een eigen holding wordt gemaakt, lijkt het mij inderdaad aanbevelenswaardig om de a.b.-regeling uit het wetsontwerp I.B. te schrappen.

\section{DE BELASTINGDRUK OP DE WINSTEN VAN BESLOTEN NAAMLOZE VENNOOT- SCHAPPEN IN VERGELIJKING MET ANDERE BEL.ASTINGPLICHTIGEN}

Aan de in de vorige paragrafen besproken onderdelen van de nieuwe wetsontwerpen I.B. en $\mathrm{Vpb}$. ligt een bepaalde opvatting ten grondslag over de fiscale positie van de besloten N.V.-en en haar aandeelhouders. Deze opvatting zou zó kunnen worden omschreven, dat ook deze N.V.-en bij een voldoende winst eigenlijk een passend aan de progressieve I.B. onderworpen dividend behoren uit te keren. Doen zij dit niet, dan moet de fiscus zich bij latere gebeurtenissen als herkapitalisatie, inkoop van eigen aandelen, verkoop a.b.-pakket e.d. schadeloos stellen voor de ontstane achterstand.

Teneinde de juistheid van dit uitgangspunt te toetsen, lijkt het nuttig de fiscale positie van besloten N.V.-en en haar aandeelhouders te vergelijken met die van: a. grote open naamloze vennootschappen;

b. vennootschappen onder firma voor soortgelijke bedrijven.

ad a.

De grote open N.V.-en plegen jaarlijks een zeker dividend uit te keren, waarover de aandeelhouders - voor zover zij in Nederland wonende natuurlijke personen zijn - I.B. betalen naar het progressieve tarief. Dit dividend is gewoonlijk echter slechts een relatief klein deel van de totale jaarwinst, bij wijze van benadering te stellen op $1 / 3$ van die winst nà aftrek van $\mathrm{Vpb}$. (zie ook inaugurele rede van Prof. Dr. A. Th. de Lange, pagina 18).

Ter benadering van de gezamenlijke druk van Vpb. en I.B. wordt uitgegaan van de volgende praemissen: 
- Tarief Vpb. $47 \%$ (weliswaar wordt reeds enige jaren achtereen terugkeer tot het tarief van $43 \%$ aangekondigd, doch telkens weer ,op termijn”).

- Tarief I.B. over uitgedeelde winsten gemiddeld $50 \%$.

- Uitkering $1 / 3$ van de winst minus $\mathrm{Vpb}$. is circa $18 \%$ van de oorspronkelijke winst.

Vpb. $47 \%$ minus reductie over de uitgedeelde winst

$(15 \% \operatorname{van} 18 \%=$ ca. $3 \%)=$

$44 \%$

I.B. $50 \%$ van $18 \%=$

Totaal

Hier komt nog bij de latente claim I.B. op het niet-uitgekeerde deel van de winst, doch deze claim blijft doorgaans tot in lengte van jaren latent - behoudens bij een enkele (gefacilieerde) herkapitalisatie - en kan daarom vrijwel worden verwaarloosd. Stel de totale belastingdruk op $55 \%$.

De aandeelhouders kunnen door verkoop de meerdere winst - w.o. de inflatie„winst" - I.B.-vrij realiseren.

De besloten N.V.-en keren dikwijls weinig of geen normaal dividend uit. Dit geldt met name voor de kleinere familie-N.V.-en, die nog in het groei-stadium verkeren. In zoverre heeft de fiscus dus een achterstand in vergelijking met de grote open N.V.-en. Hier staat tegenover:

1. Door de sterke verbondenheid aan een of enkele natuurlijke personen is de kans op liquidatie groter dan bij de open N.V., waar deze kans practisch te verwaarlozen is. Alsdan vindt heffing van I.B. plaats, weliswaar naar een gematigd tarief, doch over de gebele opbrengst boven het gestorte kapitaal, inclusief de inflatie-,,winst”.

2. Indien na het overlijden van de oprichter(s) geen liquidatie plaats vindt, is het toch in vele gevallen nodig middelen aan de N.V. te onttrekken. Zou inkoop van aandelen fiscaal conform het in de vorige paragraaf voorgestelde behandeld worden als gedeeltelijke liquidatie, dan zou over de tot uitdeling gebrachte winsten I.B. worden geheven naar een gematigd tarief.

3. De besloten N.V. is voor het aanpassen van haar aandelenkapitaal aan de groei van het bedrijf in veel sterkere mate dan de open N.V. aangewezen op herkapitalisatie. Indien deze herkapitalisatie fiscaal mogelijk zou worden gemaakt, vindt wederom I.B.-heffing plaats naar een gematigd tarief.

4. Indien de a.b.-regeling gehandhaafd blijft, vindt ook bij verkoop heffing van I.B. plaats naar een gematigd tarief en wel (in het algemeen) over het gebele bedrag van de reserves der N.V., voor zover deze tot uitdrukking zijn gekomen in de verkoopprijs.

5. Door het achterwege laten c.q. beperken van dividenduitkeringen profiteert de hier bedoelde categorie van besloten N.V.-en niet of slechts weinig van de tariefsreductie $\mathrm{Vpb}$. volgens het nieuwe ontwerp. 
In de gevallen waarin de besloten N.V. in het geheel geen jaarlijks dividend uitkeert, is de druk wegens $\mathrm{Vpb} 47 \%{ }^{1}$ )

De totale belastingdruk zou dan gelijk zijn aan die bij de open N.V.-en, indien de contante reaarde van de I.B.-claims uit hoofde van de sub $1 \mathrm{t} / \mathrm{m} 4$ genoemde factoren gelijk is aan het verschil tussen deze $47 \%$ en de totale belastingdruk bij open N.V.-en, hierboven gesteld op $55 \%$. Dit verschil is $8 \%$ van de oorspronkelijke winst of circa $15 \%$ van de winst minus Vpb. Daar de nominale waarde van deze claims òf $20-40 \%$ òf $20 \%$ bedraagt, is - gezien de vrij grote kans dat één of meer der genoemde omstandigheden zich zullen voordoen - de feitelijke belastingdruk zelfs bij het geheel ontbreken van een jaarlijks dividend slechts enkele procenten lager dan die bij de open N.V.-en. Indien de besloten N.V. wèl tot dividenduitdelingen komt - waarop na overlijden van de oprichter(s) veel kans bestaat - is er van enig verschil niet of nauwelijks sprake meer.

De hier gemaakte vergelijking zou bij afschaffing van de a.b.-heffing iets meer in het voordeel van de besloten N.V. uitvallen, doch dit verschil zou slechts van beperkte betekenis zijn, gezien de overige hierboven genoemde factoren, die de I.B.-claim tot leven kunnen wekken. Het ergste wat de fiscus bij afschaffing van de a.b.-heffing op de voorwaarden aan het slot van paragraaf 4 vermeld kan overkomen, is dat een a.b.-houder jarenlang geen enkel dividend uitkeert, nimmer aandelen aan de N.V. verkoopt nòch ze inbrengt in een holding, nimmer herkapitaliseert en tenslotte zijn a.b.-pakket verkoopt aan een derde, die bedrijfsmatig handelt. Alsdan verschilt de feitelijke belastingdruk inderdaad $8 \%$ met die van de open N.V. Dit geval is echter bij een familie-N.V. niet het normale. Doorgaans zal het verschil - indien al aanwezig - veel geringer zijn.

Het voorgaande kan niet meer zijn dan een globale benadering van een gemiddelde. De werkelijke belastingdruk wordt voor iedere N.V. in beide categorieën bepaald door de uitdelingspolitiek. Het geringe verschil in gemiddelde druk tussen beide categorieën wetrigt echter wel de conclusie dat het uit een oogpunt van rechtsgelijkheid onjuist is om aan de besloten N.V.-en bij herkapitalisatie en inkoop van eigen aandelen zulke uiterst zware voorwaarden op te leggen als het nieuwe wetsontwerp I.B. doet. Dit klemt temeer, omdat daardoor in een aantal gevallen het voortbestaan van de onderneming metterdaad in het geding zal komen.

ad $b$.

Een groot aantal familie-N.V.-en is ontstaan uit vennootschappen onder firma of eenmanszaken, waarbij niet zelden het doorslaggevend motief voor de wijziging van rechtsvorm gelegen was in het rigoureuze I.B.-tarief, dat een normale ontwikkeling van het bedrijf in de weg stond.

Wanneer bij een eenmans-N.V. de directeur-aandeelhouder een arbeidsbeloning geniet van $f 30.000$, - is voor dat deel van het inkomen de belastingdruk bij beide rechtsvormen gelijk. Zou er vervolgens nog $f 30.000,-$ worden verdiend - dus in totaal $f 60.000$, - - dan zou over laatstgenoemd deel van de winst circa $50 \%$ a $55 \%$ I.B. verschuldigd zijn (afhankelijk van gezinssamenstelling, overig

1) Een aantal N.V.-en profiteert van het iets lagere tarief $V_{p b}$. over winsten beneden $f 50.000$, 一, doch dat tarief is uitdrukkelijk bedoeld als een tegemoetkoming aan kleine N.V.-en, zodat dit punt in de vergelijking geen rol mag spelen. 
inkomen etc.), welke druk ongeveer overeenkomt met die van de gemiddelde open en besloten N.V. Bij een totaalwinst van $f 60.000,-$ per firmant is de druk bij beide rechtsvormen dus ongeveer gelijk. Bij grotere winsten is de N.V.-vorm, uitgaande van een sobere uitdelingspolitiek, fiscaal goedkoper.

Toch zou het m.i. onjuist zijn om uit het vorenstaande te concluderen dat de besloten N.V. (en dus, gezien de conclusie onder ,ad a.", óók de open N.V.) fiscaal "begunstigd" wordt. Het is immers aan gerechte twijfel onderhevig of onze exhorbitante marginale I.B.-tarieven uit een oogpunt van algemeen economisch belang te handhaven zouden zijn, indien niet de kleinere en middelgrote bedrijven de rechtsvorm van de N.V. konden kiezen.

\section{CONCLUSIES}

a. In de bepalingen van de nieuwe belastingontwerpen die de fiscale positie van de besloten N.V.-en raken, heeft teveel de gedachte voorgezeten, dat een heffing van I.B. naar het progressieve tarief over de winsten na betaling van Vpb. normaal zou zijn.

b. Vergelijking van de belastingdruk van besloten N.V.-en met die van open N.V.-en wettigt niet de conclusie dat eerstgenoemde categorie N.V.-en fiscaal begunstigd wordt. Vergelijking van de belastingdruk van alle categorieën naamloze vennootschappen met vennootschappen onder firma etc. leidt tot de conclusie dat de N.V.-vorm fiscaal minder kostbaar is. Deze conclusie mag geen argument zijn voor het creëren van knelpunten voor de besloten N.V.-en, omdat: 1. dit rechtsongelijkheid zou scheppen ten opzichte van de open N.V.-en.

2. het zeer hoge marginale I.B.-tarief geen maatstaf voor beoordeling mag zijn.

c. De tariefsreductie Vpb. over uitgedeelde winsten is te gering om voor de besloten N.V.-en een voldoende prikkel te scheppen tot dividenduitdeling.

d. De continue herkapitalisatie-regeling volgens het wetsontwerp I.B. is voor de besloten N.V.-en een dode letter, doch staat het tot stand komen van een effectieve (tijdelijke) regeling in de weg, en vormt daardoor een nieuw knelpunt in de belastingheffing. Het zal de ontwikkeling van besloten tot open N.V. ten zeerste in de weg staan. Een continue regeling is wel gewenst, doch dan met geen verdergaande eisen dan de wet op de Herkapitalisatie 1957 bevatte.

e. Een tweede knelpunt wordt gevormd door de regeling met betrekking tot de inkoop van eigen aandelen. Uit een oogpunt van redelijkheid en ter vermijding van een in vele gevallen dreigende impasse, is het nodig de koopprijs minus gestort kapitaal niet hoger te belasten dan met het bijzonder tarief.

f. De heffing van I.B. over winsten uit a.b. is in principe aanvaardbaar om een lek in de heffing te voorkomen. Het bezwaar tegen zulk een heffing is echter dat een zeer ingewikkelde regeling nodig is, die desondanks op enige zeer essentiële punten niet op de genoemde ratio past.

Uit practische overwegingen verdient het daarom aanbeveling de a.b.-regeling af te schaffen. Alsdan zou naast een regeling omtrent de fiscale gevolgen van inkoop van eigen aandelen (zie e) een voorziening moeten worden getroffen terzake van inbreng van aandelenpakketten in een holding, strekkende om de claim I.B. hetzij tegen matig tarief af te rekenen hetzij door te schuiven. Zulk een regeling zou niet méér lacunes bevatten dan de thans voorgestelde a.b.regeling.

Langs deze weg zou op veel eenvoudiger wijze dan via de a.b.-heffing een aanvaardbare oplossing voor de problematiek van de besloten N.V. kunnen worden verkregen. 